Abstract E-199 Table 1 Patients, aneurysms and device characteristics

\begin{tabular}{|c|c|c|c|c|c|c|c|c|c|}
\hline & Age & Location & $\begin{array}{l}\text { Type of } \\
\text { Aneurysm }\end{array}$ & Slze (maximal diameter) & UA/RA & $\begin{array}{c}\text { Size of } \\
\text { Surposs Evolve }\end{array}$ & $\begin{array}{l}\text { Intraprocedural } \\
\text { complication }\end{array}$ & $\begin{array}{l}\text { Post } \\
\text { Procedural } \\
\text { Complication }\end{array}$ & $\begin{array}{l}\text { Immediate } \\
\text { Radiologkal } \\
\text { Outcome (OKM) }\end{array}$ \\
\hline 1 & 58 & Right ICA & Saccular & $10 \mathrm{~mm}$ & UA & $4 \times 15 \mathrm{~mm}$ & No & No & A3 \\
\hline 2 & 61 & Left ICA & Saccular & $4 \mathrm{~mm}$ & UA & $4.5 \times 20 \mathrm{~mm}$ & No & No & A1 \\
\hline 3 & 56 & Lef ICA & Saccular & $5 \mathrm{~mm}$ & UA & $5 \times 20 \mathrm{~mm}$ & No & No & 83 \\
\hline 4 & 62 & Rieht ICA & Saccular & $4 \mathrm{~mm}$ & UA & $4.5 \times 15 \mathrm{~mm}$ & No & No & C2 \\
\hline 5 & 52 & Left ICA & Saccular & $4 \mathrm{~mm}$ & UA & $4.5 \times 17 \mathrm{~mm}$ & No & No & c3 \\
\hline 6 & 52 & Left MCA trunk & Saccular & $4 \mathrm{~mm}$ & UA & $3.25 \times 12 \mathrm{~mm}$ & No & No & 83 \\
\hline 7 & 66 & Basilar trunk & Saccular & $6 \mathrm{~mm}$ & RA & $4 \times 12 \mathrm{~mm}+4 \times 12 \mathrm{~mm}$ & No & No & $C_{2}$ \\
\hline 8 & 57 & Left MCA trunk & Saccular & $3 \mathrm{~mm}$ & UA & $2.5 \times 12 \mathrm{~mm}$ & No & No & ca \\
\hline 9 & 72 & Rieht ICA & Seccular & $10 \mathrm{~mm}$ & UA & $4.5 \times 25 \mathrm{~mm}$ & No & No & 82 \\
\hline 10 & 59 & Left Vertebral & Saccular & $3 \mathrm{~mm}$ & RA & $3.25 \times 17 \mathrm{~mm}$ & No & No & 82 \\
\hline 11 & 30 & Left ICA & Saccular & $3 \mathrm{~mm} / 3 \mathrm{~mm}$ & UA & $4.5 \times 17 \mathrm{~mm}$ & No & No & 83 \\
\hline 12 & 64 & Right ICA & saccular & $6 \mathrm{~mm}$ & UA & $4 \times 12 \mathrm{~mm}$ & No & No & $\mathrm{c} 3$ \\
\hline 13 & 66 & Rieht ICA & Sacculer & $4 \mathrm{~mm}$ & UA & $4.5 \times 17 \mathrm{~mm}$ & No & No & A3 \\
\hline 14 & 61 & Left ica & Saccular & $24 \mathrm{~mm}$ & UA & $5 \times 20 \mathrm{~mm}$ & No & No & 83 \\
\hline is & 52 & Right ICA & Saccular & $15 \mathrm{~mm}$ & UA & $5 \times 20 \mathrm{~mm}$ & No & No & A3 \\
\hline 16 & 48 & Left ICA & Saccular & $4 \mathrm{~mm}$ & UA & $5 \times 20 \mathrm{~mm}$ & No & No & $\mathrm{A}_{1}$ \\
\hline 17 & 48 & Rieht ICA & Saccular & $6 \mathrm{~mm}$ & UA & $5 \times 20 \mathrm{~mm}$ & No & No & A3 \\
\hline 18 & 60 & Left ICA & Saccular & $18 \mathrm{~mm}$ & UA & $4 \times 20 \mathrm{~mm}$ & No & No & A3 \\
\hline 19 & 41 & Left ICA & Saccular & $7 \mathrm{~mm}$ & UA & $4.5 \times 15 \mathrm{~mm}$ & No & No & A3 \\
\hline 20 & 32 & Left ICA & Saccular & $10 \mathrm{~mm}$ & UA & $4 \times 17 \mathrm{~mm}$ & No & No & 83 \\
\hline 21 & 32 & Left ICA & Saccular & $4 \mathrm{~mm}$ & UA & $4.5 \times 17$ & No & No & AB \\
\hline 22 & 70 & Rieht ICA & Saccular & $14 \mathrm{~mm}$ & UA & $4.5 \times 15 \mathrm{~mm}+4.5 \times 12 \mathrm{~mm}$ & No & No & A3 \\
\hline 23 & 42 & Right ICA & Saccular & $18 \mathrm{~mm}$ & UA & $4.5 \times 25 \mathrm{~mm}$ & No & No & 83 \\
\hline 24 & 49 & Right ICA & Saccular & $7 \mathrm{~mm}$ & UA & $5 \times 15 \mathrm{~mm}$ & No & No & A2 \\
\hline 25 & 68 & Rient ICA & Baster & $3 \mathrm{~mm}$ & UA & $4.5 \times 12 \mathrm{~mm}$ & No & No & A1 \\
\hline 26 & 55 & Right Vertebral & Fusiform & $6 \mathrm{~mm}$ & RA & $3.25 \times 20 \mathrm{~mm}$ & No & No & C3 \\
\hline 27 & 52 & Vertebrobasilar & Fusitorm & $28 \mathrm{~mm}$ & RA & $5 \times 40 \mathrm{~mm}$ & No & No & 83 \\
\hline
\end{tabular}

results from intracranial aneurysms treated with this new generation flow diverter device, SE.

Results Twenty-eight aneurysms (86\% unruptured) were treated with twenty-nine SE devices. All procedures were technically successful. In one aneurysm (case \#26), a coil was used to secure the thrombosis. At discharge, all patients had a modified Rankin score of $0-2$. No intraprocedural or thromboembolic complications were encountered. One subarachnoid hemorrhage (SAH) occurred one week after the treatment (case \#22), and this patient died due to SAH. The median follow-up time was two months (range; 0-6 months). The radiological follow-up data was available for nine patients (33\%); two aneurysms were occluded during the follow-up period.

Conclusions Our initial experience with the new generation $\mathrm{SE}$ indicates that the device is safe to use. The new generation SE provides reliable deployment and lower foreshortening. Mid-term and long-term follow-up examinations will be needed to provide data on longer term safety outcomes.

Disclosures K. Alpay: None. R. Rautio: 2; C; Microvention, Stryker, Medtronic. J. Numminen: None. M. Sinisalo: None.

\section{E-200 GENDER AND RACIAL DISPARITY IN OUTCOME OF ANEURYSMAL SUBARACHNOID HEMORRHAGE IN THE UNITED STATES}

S Majidi, A Mehta, B Yim, K Yaeger, R De Leacy, J Mocco, J Fifi. Neurosurgery, Mount Sinai Hospital, New York, NY

\subsection{6/neurintsurg-2020-SNIS.231}

Background Aneurysmal subarachnoid hemorrhage (aSAH) is associated with a high rate of morbidity and mortality. We aimed to assess the prognostic impact of gender and race in these patients.
Methods The Nationwide Inpatient Sample (NIS 2006-2016) was utilized to identify patients presenting with aSAH as primary diagnosis. Patient age, sex, race/ethnicity, insurance status, socioeconomic status, comorbidities, type of the hospital and treatment modality used for aneurysm repair were extracted. The previously validated NIS-SAH Severity Scale was used to estimate the clinical severity. Discharge destination and in-hospital mortality were used as outcome measures. The impact of race and gender on clinical outcome was analyzed using multivariate regression models.

Results A total of 19,512 patients with aSAH were identified. Mean age $( \pm S D)$ was $54( \pm 0.1)$. Sixty seven percent of the patients were female, $49 \%$ white and $13 \%$ black. Female patients were 4 years older (55 vs $51, \mathrm{p}<0.0001$ ), and had higher numbers of comorbidities. There was no difference in the NIS-SAH Severity Scale score between the two genders. Women had significantly lower odds of good clinical outcome (defined as discharge to home or acute rehabilitation facility) after adjusting for confounding factors [OR, (95\% CI); pvalue: $0.88,(0.81-0.96) ; \mathrm{p}<0.0001]$. In regard to race, Hispanic patients [OR, (95\% CI); p-value: 1.49, (1.29-1.72); $\mathrm{p}<0.0001$ ] and Asians [OR, (95\% CI); p-value: 1.33, (1.07$1.64) ; \mathrm{p}<0.0001]$ had higher odds of good clinical outcome after adjusting for age, gender, $\mathrm{SAH}$ severity, comorbidities and treatment modality. Lower odds of mortality was observed in black [OR, (95\% CI); p-value: 0.55, (0.46-0.66); $\mathrm{p}<0.0001$ ] and Hispanic patients [OR, (95\% CI); p-value: $0.72,(0.59-0.88) ; p=0.001]$ compared to the white patients.

Conclusions In this nationally representative study, women and white patients had disproportionately higher likelihood of poor clinical outcome. Lower rate of mortality is seen among black and Hispanics.

Disclosures S. Majidi: None. A. Mehta: None. B. Yim: None. K. Yaeger: None. R. De Leacy: None. J. Mocco: None. J. Fifi: None. 